Aletria, Belo Horizonte, v. 29, n. 1, p. 217-222, 2019

\title{
ANDERMANN, Jens. Tierras en trance: arte y naturaleza después del paisaje. Santiago de Chile: Ediciones Metales Pesados, 2018. 462 p.
}

Eneida Maria de Souza

Universidade Federal de Minas Gerais (UFMG), Belo Horizonte, Minas Gerais / Brasil eneidamariasouza@gmail.com

A obra de Jens Andermann, Tierras em trance, publicada em 2018, merece ser lida por toda a comunidade acadêmica latino-americana e de outras regiões, não só pela originalidade do enfoque como pela inteligente associação entre várias áreas do conhecimento, incluindo literatura, arquitetura, artes plásticas e cinema. Trata-se da exploração de uma série de constelações artísticas em torno dos séculos XX e XXI, com alusões bem nítidas às transformações teóricas e políticas ocorridas no período. Com uma proposta que visa ressaltar o sentido inespecífico dessas manifestações, ao empregar procedimentos analíticos inscritos nas mesclas, interfaces e hibridismos, o texto inova pela crítica e pela reconfiguração da relação entre "arte e natureza depois da paisagem", com base num pensamento ecológico e político. De extrema atualidade, o alentado ensaio discorre sobre as mudanças ocorridas nos conceitos tradicionais vinculados à estetização da natureza, ao apresentar categorias analíticas tais como antropoceno, transe, hiperobjeto, com o intuito de romper com a separação moderna entre homem/natureza/animal.

A fala das forças naturais, contradizendo a fala forasteira dos viajantes, ao permitir a entrada no universo não humano - capaz de se expressar e atuar politicamente -, encontra-se presente nas narrativas escolhidas pelo autor como exemplo do conceito de antropoceno, definido como "idade geológica na qual haveria colapsado a distinção 
entre história humana e história natural, o que faria necessário", ${ }_{1}^{1}$ como expressa Dipesh Chakrabarty em "Clima e historia: cuatro tesis", "colocar as histórias globais do capital em diálogo com a história do homem como espécie". ${ }^{2}$ A acepção de transe, própria das religiões afro-americanas, define-se no âmbito da transformação e da metamorfose, em resposta à visão continuísta e homogênea da modernidade. Andermann vale-se do raciocínio de Gilles Deleuze na explicação do transe, o qual se manifesta, entre outros registros, nos filmes de Glauber Rocha e Youssef Chahine, pela emergência de enunciados coletivos que "contribuem para a invenção de um povo". ${ }^{3}$ O povo, entendido como possibilidade do sujeito político coletivo ainda por vir no Terceiro Mundo, deve passar pelo transe, uma das modalidades críticas do mito. Por isso sua caracterização, ainda segundo Deleuze, responde pela ideia de transição, passagem ou devir, sendo o que possibilita o ato de fala e se desconecta da noção de progresso. ${ }^{4}$ Mas a perspectiva de Andermann, inscrita na valorização da natureza como força, convoca a alteração do "devir povo" deleuziano pela expressão do poeta argentino Juan Lópes Ortiz, ao declarar: "“o povo é a natureza' ou, melhor, 'as coisas naturais e não a natureza". 5

$\mathrm{Na}$ mesma linhagem, o conceito de hiperobjeto, nomeado com termos como antropoceno, capitaloceno e chthuluceno, abala as oposições e sentidos de localização e tempo, concebendo-se como viscosidade, interobjetividade e pouca visibilidade, por se desfazer da visão soberana do sujeito e se impor em proximidade com materialidades vibrantes, responsáveis pela presença de uma ecologia política. Na acepção do teórico Timoty Morton, o hiperobjeto refere-se aos materiais nucleares distribuídos massivamente nas coisas gigantescas da terra, como o

1 “[...] edad geológica en la que habría colapsado la distinción entre historia humana e historia natural y se volvería necessário [...]" (ANDERMANN. Tierras en trance: arte y naturaleza después del paisaje, p. 183, tradução minha).

2 " [...] poner las historias globales del capital en conversación con la historia del hombre en tanto especie" (CHAKRABARTY. Clima e historia: cuatro tesis, p. 212 apud ANDERMANN. Tierras en trance: arte y naturaleza después del paisaje, p. 183, tradução minha).

${ }^{3}$ ANDERMANN. Tierras en trance: arte y naturaleza después del paisaje, p. 22.

${ }^{4}$ Cf. ANDERMANN. Tierras en trance: arte y naturaleza después del paisaje, p. 22.

5 "[...] 'el pueblo es la naturaleza' o, más bien, 'las cosas naturales y no la naturaleza", (ORTIZ apud ANDERMANN. Tierras en trance: arte y naturaleza después del paisaje, p. 26, tradução minha). 
aquecimento global, a via láctea, o sistema solar ou toda maquinaria estridente e avassaladora do capitalismo. ${ }^{6} \mathrm{O}$ homem deixa de ser, nessa circunstância, o centro do universo:

O fim do mundo, sugere Timothy Morton, já está conosco: do mundo como totalidade significante, acessível exclusivamente ao espírito humano - porém, "este momento é o começo da história, o fim do sonho humano de que a realidade é significante unicamente para eles."

Com forte tendência a desconstruir discursos coloniais e novecentistas de imaginar o Novo Mundo, Andermann percorre uma gama heteróclita de discursos que vão das obras literárias e plásticas a construções arquitetônicas e cinematográficas, por meio de uma proposta analítica comparativa e transdisciplinar. Os estudos culturais da América Latina estavam prescindindo de uma abordagem mais abrangente e não exclusiva, com ênfase na contribuição conjunta de manifestações artísticas que sinalizassem diferenças e semelhanças entre elas. $\mathrm{Na}$ escolha de temas comuns, como o pensamento ecológico e político existente no interior das formas estéticas, o mérito deste trabalho reside no pioneirismo analítico e na introdução de novos modos de repensar os limites da modernidade e a abertura de caminhos interpretativos. Pela perspectiva comparativa, deslocam-se a preocupação identitária das regiões, as noções de gênero e disciplina, ao propor a "aprendizagem de um despaisamento" oriundo das próprias obras analisadas e da produção de um corpus "desordenado e aleatório". ${ }^{8}$ Nas palavras do ensaísta, trata-se de "uma constelação caprichosa de obras que não respeita a história de suas formas, na particularidade disciplinar ou geográfica de seu aparecimento e recepção crítica, cujas conclusões, portanto, serão condenadas à tautologia ou ao delírio." 9

\footnotetext{
${ }^{6}$ Cf. ANDERMANN. Tierras en trance: arte y naturaleza después del paisaje.

7 "El fin del mundo, sugiere Timothy Morton, ya está con nosotros: del mundo como totalidad significante, accesible exclusivamente al espírito humano - pero 'este momento es el comienzo de la historia, el fin del sueño humano de que la realidad es significante únicamente para ellos.'”(ANDERMANN. Tierras en trance: arte y naturaleza después del paisaje, p. 24, tradução minha).

${ }^{8}$ ANDERMANN. Tierras en trance: arte y naturaleza después del paisaje, p. 30.

9 “" [...] una constelación caprichosa de obras que no respeta las historias de sus formas en la particularidad disciplinaria o geográfica de su emergencia y recepción critica, cuyas
} 
$\mathrm{Na}$ abertura, Andermann elege o quadro de Adriana Varejão, "Paisagens", de 1995 - cuja reprodução ilustra a capa do livro -, como mote para a apresentação da proposta sobre a narrativa da história natural ao avesso, por inverter a fisionomia das viagens pitorescas narradas pelos conquistadores. A resposta pós-colonial e feminina da paisagem contracena com a tradição da violência "falogocêntrica" (conceito derridiano), instaurando uma das configurações éticas da paisagem como forma de resistência. O desenho do chileno Miguel Lawner, de 1974, uma árvore solitária na ilha de Dawson, evoca também o extermínio da companhia madeireira de toda população indígena, assim como alegoriza, seis meses depois do golpe militar chileno, o infortúnio que acabava de cair sobre o país inteiro. ${ }^{10}$ Uma pintura e um desenho inscrevem a pauta metodológica e política do ensaio, contracenando autores da América Latina, desenvolvendo espaços estéticos como o deserto, a selva e a montanha; a revolução da paisagem da modernidade arquitetônica; a politização do espaço desencadeado pelas guerrilhas rurais e urbanas, além da denúncia de práticas da memória pós-ditatorial presente em filmes neorregionalistas.

A sensibilidade literária do ensaísta conjuga-se à tendência transdisciplinar, pela natureza inespecífica do objeto estético, capaz de ultrapassar limites e instaurar aproximações inusitadas e incomuns entre vários registros. De valor quase enciclopédico, o livro reúne um repertório extenso de autores que inclui brasileiros como Guimarães Rosa, João Cabral de Melo Neto, Graciliano Ramos, Euclides da Cunha, Mário e Oswald de Andrade, e hispânicos, como o poeta Ortiz, ficcionistas como Arlt, Juan Rulfo, Piglia, entre outros, com o objetivo de mapear as associações críticas da forma paisagem. $\mathrm{Na}$ área arquitetônica, a modernidade é interpretada de forma a definir a instauração do convívio coletivo pela construção de parques, jardins, prédios e cidades na América Latina sob a égide da criação estética. O meio de integração entre paisagem e arquitetura serviria de foco para a contribuição do modelo de modernização dos países periféricos. Lúcio Costa, Niemeyer, Villanova Artigas, no Brasil; Villagrán, O’Gorman e Del Morán, no México; Villanueva e Dominguez, na Venezuela, protagonizam as práticas de

conclusiones, por ende, serán condenadas a la tautologia o al delírio." (ANDERMANN. Tierras en trance: arte y naturaleza después del paisaje, p. 30, tradução minha). ${ }^{10}$ ANDERMANN. Tierras en trance: arte y naturaleza después del paisaje, p. 11. 
"regionalização" e vigor próprias da modernidade arquitetônica entre nós, em resposta à herança europeia.

Nas artes plásticas, Hélio Oiticica e seus parangolés inaugura, segundo Mário Pedrosa, a função do artista como guerrilheiro, pelo êxodo do espaço dos museus para as práticas cotidianas, politizando e deslocando territórios fixos e institucionais. ${ }^{11}$ A cultura do corpo infiltra-se na paisagem, da mesma forma que a arquitetura moderna dialogava com a natureza, afastando-se da visão predadora. A cubana Ana Mendieta, autora de obras performáticas e das body arts nos anos 1970, surge ao lado de Oiticica de maneira um pouco distinta, sem romper com a ideia de uma estética desconstrutora do corpo. Representa a atuação do corpo migrante, o que seria, no entender de Andermann, a manifestação da biopolítica "pós-colonial", em que corpo e ambiente se confundem,

Do ponto de vista de uma geopolítica migrante, ao estarem ambos submetidos a uma mesma biopolítica imperial, que tornou redundante a separação entre figura e fundo, sobre a qual ainda se organizava o regime extrativo anterior, manifesto esteticamente na forma paisagem como dispositivo de transplante entre colônia e metrópole. ${ }^{12}$

Um dos pontos mais significativos do livro reside no último capítulo, que incorpora ao seu repertório as exposições que apontam as convergências entre arte e ciência, pela presença de bioartistas e ecoartistas. Sinaliza a importância dos filmes pós-ditadura na América Latina, com especial ênfase em La nostalgia de la luz, de Patricio Gusmán, além de representantes brasileiros desta fase. Os desertos do Sul e os sertões nordestinos ilustrariam a violência constitutiva do Estado moderno, agora revisitados pela nostalgia de um tempo utópico. Seria, no meu entender, a síntese da proposta teórica e política do autor, por reivindicar a bioarte e a arte ecológica como saída para o rompimento da separação entre estética e técnica, natureza e cultura, arte e política.

\footnotetext{
${ }^{11} \mathrm{Cf}$. ANDERMANN. Tierras en trance: arte y naturaleza después del paisaje.

12 " "....] desde el punto de vista de una geopolítica migrante, al estar sometidos, ambos, a una misma biopolítica imperial que ha hecho redundante la separación entre figura y fondo sobre la que estaba organizado todavía el régime extrativo anterior, manifestado esteticamente en la forma paisaje como dispositivo de transplatación entre colonia y metrópoli." (ANDERMANN. Tierras en trance: arte y naturaleza después del paisaje, p. 334, tradução minha).
} 
A abordagem aí efetuada, com ênfase na condição pós-natural da estética e na definição da pós-paisagem, em virtude do esgotamento de sua atuação, inscreve-se de modo pioneiro e original para o avanço dos estudos literários e culturais do momento. Descartando estereótipos empregados na produção de discursos periféricos, nos quais o ressentimento atuava como solução para a violência colonialista, Tierras en trance assume dicção positiva e se impõe como resistência ao devir-transe. Como o título da obra especifica, o autor convida o leitor a vivenciar, pela experiência transformadora do transe, novas perspectivas e a acreditar na "promessa de um entendimento transespécie, uma estética líquida que não é outra, no final das contas, que o transe da terra que dá título a este livro: a circulação, o vibrar, do sólido."13

O livro atua, sem dúvida, como alerta para os problemas vividos pela América Latina nos dias atuais, em que são abalados princípios de cidadania e de liberdade de expressão, pela imposição de valores vinculados à prática de um capitalismo selvagem e excludente. Política e arte se conjugam por intermédio da revisão de teorias revolucionárias contidas nas práticas da bioarte e da biopolítica. Rompe-se com a visão romântica e alienada da natureza ao elegê-la como entidade múltipla e transformadora e ao reivindicar saídas positivas para embates literários e culturais.

\section{Referência}

ANDERMANN, Jens. Tierras en trance: arte y naturaleza después del paisaje. Santiago de Chile: Ediciones Metales Pesados, 2018. 462 p.

Recebido em: 29 de janeiro de 2019. Aprovado em: 18 de março de 2019.

13 “[...] promesa de un entendimiento transespecie, una estética líquida que no es otra, a fin de cuentas, que el trance de la tierra que da título a este libro: la puesta en circulación, el vibrar, de lo sólido." (ANDERMANN. Tierras en trance: arte y naturaleza después del paisaje, p. 29, tradução minha). 